Article

\title{
Moving Targets and Biodiversity Offsets for Endangered Species Habitat: Is Lesser Prairie Chicken Habitat a Stock or Flow?
}

\section{Todd K. BenDor ${ }^{1, *}$ and Sierra Woodruff ${ }^{2}$}

1 Department of City and Regional Planning, University of North Carolina at Chapel Hill, CB \#3140, New East Building, Chapel Hill, NC 27599, USA

2 Curriculum for the Environment and Ecology, University of North Carolina at Chapel Hill, CB \#3275, 3301 Venable Hall, Chapel Hill, NC 27599, USA; E-Mail: sscheleg@live.unc.edu

* Author to whom correspondence should be addressed; E-Mail: bendor@unc.edu; Tel.: +1-919-962-4760; Fax: +1-919-962-5206.

Received: 9 January 2014; in revised form: 28 February 2014 / Accepted: 4 March 2014 / Published: 10 March 2014

\begin{abstract}
The US Fish and Wildlife Service will make an Endangered Species Act listing decision for the lesser prairie chicken (Tympanuchus pallidicinctus; "LPC") in March 2014. Based on the findings of a single, Uzbek antelope study, conservation plans put forth for the LPC propose to modify and re-position habitat in the landscape through a series of temporary preservation/restoration efforts. We argue that for certain species, including the LPC, dynamic habitat offsets represent a dangerous re-interpretation of habitat provision and recovery programs, which have nearly-universally viewed ecosystem offsets (habitat, wetlands, streams, etc.) as "stocks" that accumulate characteristics over time. Any effort to create a program of temporary, moving habitat offsets must consider species' (1) life history characteristics, (2) behavioral tendencies (e.g., avoidance of impacted areas, nesting/breeding site fidelity), and (3) habitat restoration characteristics, including long temporal lags in reoccupation. If misapplied, species recovery programs using temporary, moving habitat risk further population declines.
\end{abstract}

Keywords: endangered species; habitat offsets; environmental markets; dynamic habitat 


\section{Introduction}

The development and spread of wetland and stream mitigation in the United States has functioned as a model for emerging ecosystem markets, including water quality trading (e.g., nitrogen markets) [1] and endangered species habitat offsets (e.g., conservation banking) [2], in the United States and other nations (e.g., Australia, Brazil, Colombia, and South Africa). Substantial literature has focused on the use of biodiversity markets for conserving endangered species, whereby impacts to habitats are viewed as species "takes", and are required to be offset through habitat preservation and/or restoration in another location [2]. A good deal of work has attempted to draw connections between the type of market-based incentive mechanisms seen in wetland and stream markets with the specific habitat needs of species targeted for conservation [3].

In this paper, we will similarly remark on the nature of ecosystem markets, particularly as they can be viewed as "stocks" or "flows"; flows being trades of nearly instantaneously obtainable and transient commodities or conditions to be traded in a market, and stocks being the accumulations of those flows or conditions over longer time periods. In drawing this important distinction between different types of ecological markets, we pose a simple question - one whose answer may change depending on the exact policy application: Should the restoration or preservation of species habitat represent a "stock" or a "flow" of ecological services across the landscape?

We pose this question in response to the recently proposed application of the concepts introduced by Bull et al. [4] for a species potentially receiving federal protection under the Endangered Species Act. Bull et al. [4] provide insight into conservation techniques for species whose habitat is particularly difficult to safeguard. The authors propose the use of temporary habitat offsets that can shift along with species whose habitat "moves" in space, as a result of migratory behaviors or environmental changes (e.g., climate change). In developing their conception of dynamic habitat offsets, the authors cite Poiani et al. [5] who sampled 20 existing conservation projects, estimating that "...more than half would require major alterations if climate-change impacts were considered. In cases where species' ranges are projected to shift in response to climate change, mobile [protected areas] could facilitate conservation". Bull et al. [4] go on to argue that the effectiveness of permanent protected areas may be compromised when conservation targets are not stationary. For example, stationary protected areas fail to protect migratory species over their life cycle. Bull et al. [4] provide an interesting (and convincing) application of dynamic habitat offsets to the saiga antelope in Uzbekistan.

Our interest in dynamic habitat offsets arises from the recent range-wide plan created by the Western Association of Fish and Wildlife Agencies (WAFWA) to protect the lesser prairie chicken (Tympanuchus pallidicinctus; "LPC"), a member of the grouse family that has experienced precipitous decline over the last decade throughout its range in the United States Southern Great Plains [6,7]. This range-wide plan is innovative in many ways and represents an elevated level of coordination by the US states containing LPC habitat in an attempt to avert a potential collision between rapid energy production and LPC recovery. However, we would argue that the application of Bull et al.'s [4] species conservation insights to the LPC represent a dangerous re-interpretation of endangered species habitat provision (and endangered species conservation, generally) as a "flow" in the landscape.

The idea that habitat can be modified and spatially re-positioned through a series of temporary preservation/restoration efforts, is a substantial departure from previous recovery programs, which 
have viewed ecosystem offsets (habitat, wetlands, streams, etc.) as "stocks" that accumulate characteristics over time [8]. In addition, the range-wide plan's proposed dynamic habitat offsets do not adequately consider the LPC's (1) life history characteristics, (2) behavioral tendencies (such as avoidance of previously impacted areas or inclinations towards specific nesting zones), and (3) habitat restoration characteristics, including long temporal lags in habitat establishment. While the Lesser Prairie-Chicken may be particularly ill-suited for temporary habitat offsets, the issues that arise in this case are not unique and must be considered in other habitat markets considering temporary habitat conservation to offset permanent impacts.

\section{A Range-Wide Plan for Protecting the LPC}

WAFWA's plan represents an effort by five state governments to preclude a formal listing of the LPC by the US Fish and Wildlife Service (FWS) under the US Endangered Species Act (16 USC 1531-1544). If formal listing is not avoided, and the LPC is listed as a "threatened" species (one step under an "endangered" determination), then WAFWA may be granted an exemption (known as a 4(d) ESA exemption) under its proposed plan. In this case, landowners participating in the WAFWA plan may continue development and landscape impacts as long as they comply with the plan (which is intended to have a net benefit for the species). Although the USFWS remains the ultimate arbiter of whether a species is being adequately protected, a 4(d) exemption would delegate much of the authority of LPC conservation to WAFWA.

WAFWA's plan heavily leverages biodiversity offsets (the terms "mitigation" and "offsets" are dependent on the specific market, but are used interchangeably here), whereby habitat that is impacted by development (typically oil and gas extraction or electric/road infrastructure), is offset by restoration or preservation of grasslands habitat elsewhere. However, unlike previous efforts to create permanent habitat restoration or preservation sites (as seen in the USFWS [8] Guidance on Conservation Banking), WAFWA [7] (p. 93), attempts to make offsets heavily dynamic in the landscape, drawing on the logic put forth by Bull et al. [4]:

- "The WAFWA Mitigation Framework will implement two separate mitigation trading markets, one based on short-term (5-10 years) contracts and another focusing on long-term conservation. The need for this two-market system is based on LPC biology, habitat stochasticity, and anticipation of population shifts brought on by changing climatic conditions. Unlike other grouse species, LPC appear to be adaptable to changing habitat conditions (i.e., structure, grass species composition etc.), which can be created in a relatively short time period (within 2-8 years) [...]."

- "This moving conservation concept is further supported by a recent study that cautions against using traditional conservation strategies involving static tools (e.g., protected areas that have fixed spatial boundaries). J.W. Bull et al. [4] discuss the difficulty of implementing conservation for "moving targets" such as migratory species or landscapes subject to environmental change. The observations made by J.W. Bull and others about landscapes are similar to those observed within the range of the LPC. They propose approaches for dealing with "moving" conservation targets by including mobile protected areas, which follow their targets across the landscape." 
Bull et al.'s [4] study, which argues that flexibility in offsets are key to species conservation, is used to justify WAFWA's determination to implement $75 \%$ of all offsets as a series of temporary contracts with landowners. WAFWA may also place emphasis on temporary contracts because the majority of LPC habitat (95\%) occurs on privately owned lands and effective conservation of LPC is likely to require significant support from private parties [7]. Permanent conservation is expensive and often requires extended management to maintain suitable habitat conditions for target species. Dynamic habitat conservation is intended to quickly affect change in habitat condition over a larger spatial extent. Due to the pervasiveness of these conservation challenges, temporary offsets suggested in the WAFWA plan seems to be indicative of future conservation offset efforts for other species [9]. The growing prevalence of temporary contracts in offset markets emphasizes the need for careful evaluation of the consequences of relying on dynamic habitat conservation to offset permanent impacts.

\section{Ecosystem Markets: Trading Stocks or Flows}

In exploring whether LPC habitat should be considered a "stock" or a "flow", we can draw on previous work in U.S. aquatic mitigation markets, which include U.S. Clean Water Act Section 404 (33 USC 1344) mitigation markets for wetlands and streams [10], and more recently, water quality offset markets [11]. Efforts to draw analogies and gain lessons from the nearly 30 years of wetland market implementation have included relevant work by Raffini and Robertson [12] and Robertson and Mikota [11], who explore policy differences between water quality trading and wetland markets.

Perhaps the most relevant difference is the fact that water quality markets, at least as they have been articulated under US Policy, are a function-based "flow" market, wherein trades are typically articulated as contracts leading to changes in land management actions that temporarily decrease water pollution, usually on a yearly basis. That is, payments lead to temporary improvements in water quality, which can be initiated or severed at any time, and which must be repeated year after year. A lack of trades can lead to low water quality in one year, and widespread and well-enforced contracts can lead to vast improvements in water quality the next year. Depending on the regulated water body (e.g., in-stream water $v s$. an estuary), the location and time extent of water quality management actions may be of little importance as long as the overall water quality in a water body is improved on an immediate time scale [13]. Water quality credits represent a function-based commodity defined by a single function: typically denitrification, phosphorus sequestration, or sediment retention [11]. The result of this is that the quality of water in a body (typically a river system) does not accumulate (at least not as interpretable under recent policies); it is an attribute of a continually flowing system.

This contrasts markets for wetlands or streams themselves, which trade credits based on overall conditions, "stocks" or a "bundle of functions". While single function measures, such as vegetation cover, may be used to assess mitigation sites, these serve as a proxy for a range of ecosystem functions [14]. Condition-based credits recognize that ecosystem functions are intertwined and that the complex connections between functions remain largely unknown and unquantified [11]. Restoration of wetlands and streams takes years or decades to produce adequate or stable ecological functions. If management actions cease, the wetland or stream ecosystem conditions deteriorate and cannot be immediately reversed the following year. As a result, wetland and stream markets that trade condition-based credits 
operate inherently as "stocks" that accumulate energy inputs (e.g., plantings, hydrologic regime establishment, soil conditioning, etc.).

Robertson and Mikota [11] further argue that an important difference between markets for stocks (ecosystems) and flows (ecosystem outputs) is that flows are temporary, while stocks produce a permanent set of functions that are required to be protected and maintained for perpetuity. In the case of the LPC, we can consider both kinds of markets: as a stock, LPC credits represent functional habitat protected for perpetuity; as a flow, LPC credits represent species counts over a period of time (i.e., "chicken-years"). Differently stated, when considering if a condition- vs. function-based metric is appropriate, we must consider whether we are interested (1) in the actual condition of LPC habitat, or (2) in the population (or other habitat outputs) of LPC on habitat sites.

\section{Application to the LPC}

A fundamental question that must be addressed while evaluating the design of any market-based habitat offset system for the LPC is: Is LPC habitat a stock or a flow?

The WAFWA range-wide plan, which is primarily based on Bull et al.'s [4] dynamic habitat offset concept, treats LPC habitat as if it is a flow, providing a single function similar to water quality offsets. The plan claims that temporary contracts allow flexibility to shift conservation areas as LPC range changes due to climate change. As such, habitat offsets can fluctuate between preserved/restored habitat and other uses based on contracts that can sequentially expire [7]. While short-term conservation contracts may be beneficial to allow for long-term LPC range change that may or may not happen, these benefits must be evaluated in light of (1) the cost of habitat turnover, (2) the ability of LPC to move across the landscape and utilize newly restored habitat, and (3) the likely effectiveness of monitoring efforts.

While the location and temporal extent of water quality projects are unimportant as long as nitrogen levels are reduced in the targeted water body, biodiversity is highly sensitive to both spatial and temporal allocation of habitat [13]. In biodiversity offset markets, each trade represents destruction of a habitat patch and the populations associated with that patch; created habitat patches on the other hand must become occupied before they can contribute to species survival. Due to the difficulty of habitat restoration, some offsets may never reach expected habitat quality or support LPC populations. Thus, even when the habitat area remains constant, spatial reallocation of habitat, or "habitat turnover", can be detrimental to species viability $[13,15,16]$. Consequently, offset trading may be able to achieve the no-net loss requirement in habitat, but will do so without producing the desired conservation benefit for the species.

In a market where habitat restoration is temporary, habitat turnover will be more rapid because not only do trades result in reallocation of habitat but also the termination and creation of restoration contracts. We should note that several historic conservation programs have also used voluntary short-term contracts to good effect. The Conservation Reserve Program, perhaps the largest conservation program in the U.S., provides incentives to farmers to convert their land back to native grasslands, usually enrolling areas that are not be ideal for crop production. The Conservation Reserve Program has historically had high rates of re-enrollment, with 10-15 years contracts that result in conservation for a longer duration. However, WAFWA's plan does not ensure the same success; first, WAFWA's 
contract times are much shorter. Second, unlike the WAFWA plan, the Conservation Reserve Program has well-established mechanisms for enforcement of conservation standards. Lastly, and most importantly, the structure of these programs is fundamentally different; the conservation reserve program provides incentives for conservation (there is no damage being offset), while WAFWA uses short-term contracts to offset certain damage to LPC habitat. Voluntary, temporary contracts can play an important role in conservation, but using these mechanisms within an offset market may not result in the desired conservation benefit.

When we consider the specific life history characteristics of the LPC, habitat turnover caused by offsets and temporary contracts becomes even more problematic. LPC have high fidelity to breeding and nesting sites, returning to the same sites year after year, even when habitat becomes degraded [6]. Juvenile birds may choose new nesting sites, but their dispersal distances appear limited with an average dispersal distance of 5.3 miles [7]. High fidelity to nesting sites, low brood survival rates, and limited dispersal distances combine to call into question the LPC rate of dispersal and mobility in the landscape. The USFWS recognize the need for long-term protection to account for LPC biology [17], (p. 3):

In addition to these size requirements, strongholds [“.... areas managed or set aside for long-term LPC conservation and of sufficient size to support a viable population of LPC [7]"] must have long-term protection in place to address the species' relatively short life span, low nest success, high annual mortality, low recruitment, and high juvenile mortality. In the context of the lesser prairie-chicken, 10 to 15 years timeframes may be too short a period due to the species' life-history traits.

If the rate of landscape change is faster than the rate of dispersal, LPC may not be able to occupy new habitat patches, reproduce, and disperse before habitat becomes unsuitable and, consequently, regional populations may not survive [16]. Thus, the higher the rates of landscape change and habitat turnover, the lower the probability of regional population survival. These temporal effects can far outweigh the effects of habitat provision and location [15]. By mitigating permanent impacts with temporary, moving habitat WAFWA is suggesting a trade of certain habitat destruction for uncertain offsets.

While the biological consequences of high habitat turnover alone provide sufficient evidence to question the design of WAFWA habitat offset program, there are additional implementation drawbacks. If credits represent flows, then, similar to Robertson and Mikota's [11] argument in water quality markets, it will be difficult to monitor the status of these flow credits. It remains uncertain how to assure the production of "chicken-years" is actually occurring at credit-producing sites. For example, Dreschsler et al. [18] found information asymmetries that complicated contracting for species conservation, since landowners were found to have an incentive to overstate effort required and over-report their value of conservation. Moreover, while stock credits can use condition-based metrics for success, flows are function-based, namely chicken-years produced. While one could ideally assess the value of conservation by assessing its influence on species survival, direct monitoring may not be available or may be prohibitively expensive [19].

Can we treat LPC habitat as conditioned on management actions that can sequentially expire? Allowing the levels and locations of habitat to ebb and flow from year to year, fails to account for accumulations in terms of (1) learned avoidance behaviors [6] and (2) high site fidelity (e.g., leks, brooding, and nesting areas). Furthermore, the concept of habitat restoration needs to be evaluated in 
terms of time lags between impacts and restoration - it does not make sense to implement (relatively) short-term contracts for habitat restoration, when land restoration itself can take years to establish basic vegetative communities [20]. In the case of the LPC, habitat restoration may take in excess of eight years to establish [7], and reoccupation may take even longer.

A small literature, particularly pertaining to compensatory wetland mitigation, has recently begun to address several pertinent issues relating to the temporal delays associated with offset markets. Quétier and Lavorel [21] and Bedward et al. [20] argue that time lags in the development of habitat means offset gains may take decades to materialize, even though biodiversity losses are immediate. While restoration takes time to be ecologically successful, impact permits are not typically withheld until a replacement is deemed successful [22]. Determining ways to handle these temporal losses are critically important for the effectiveness of offsets in sustaining species habitat; Bedward et al. [20] points out that the immediate decline in habitat availability created by these temporal lags may cause a critical bottleneck in the population size that can lead to regional extinction.

Another important issue arises in the context of the "inexact" science of habitat restoration and creation. Offset projects often fail to produce habitat that can sustain the target species at the original density, or at all (see wetland examples in [23]). This is often accounted for by offsetting larger areas of habitat than are lost (see [24] and [25] for a discussion of these "offset ratio" multipliers). Little work has studied these issues in the context of habitat offsets; unless habitat restoration or creation for the LPC is particularly easy, treating it as a flow will require consistent expansion of offset area.

\section{USFWS Precedent: Endangered Species Habitat Is a Stock}

Stock and flow considerations have already entered into past USFWS reasoning, particularly in requirements that conservation banks (formalized habitat offset sites, used extensively throughout the Western United States [26]) protect land permanently:

At the time that the first credit in a bank or phase of a bank is sold, the land within the bank or its phase must be permanently protected through [permanent land purchases] or a conservation easement, with any land use restrictions set in perpetuity for the land legally established (USFWS 2003, p. 10).

The logic driving this dictum is echoed in 2008 regulations for wetland mitigation banks [26], which require permanent protections for aquatic ecosystem offsets, thereby specifically identifying them as a stock, which cannot reasonably be protected with temporary contracts.

The USFWS conservation banking guidance [8] goes on to note that:

...[c]onsequently, once any credit in a given bank or phase is sold, the entire area is automatically and legally protected, regardless if the rest of the credits in the bank or phase are sold, thereby eliminating future fragmentation of habitat.

This explicit requirement for long-term protection for habitat banks echoes requirements for non-wasting endowments for long-term monitoring and maintenance on stream and wetland restoration sites [27]. 


\section{Conclusions}

The WAFWA range-wide plan has prompted coordination by the US states containing LPC habitat and represents an important attempt to avert a potential collision between rapid energy production and LPC recovery. Furthermore, Bull et al.'s [4] application of temporary offsets to species habitat impacts represents an innovative method for dealing with dynamic habitat requirements and changing environmental conditions. However, the U.S. Endangered Species Act considers habitat destruction to be an important element in endangered species population decline; as a result, the law (and policies emerging from the law) must explicitly consider habitat to be an integral part of the species' lifecycle and life history. In the case of the lesser prairie chicken, the species' habitat is clearly an ecosystem, whose functions accrue over time. As with nearly all other ecosystem-centered markets, including wetlands, streams, previous conservation banking efforts, and even carbon offset markets [28], LPC habitat should be considered as a stock for the purposes of species recovery policies. As a result, long-term site protections must be a key feature of any market-based policy for species protection, including the proposed WAFWA habitat offset market or any other proposed markets (e.g., Habitat Credit Exchange) that rely on this type of 'dynamic permanent offsets' or 'dynamic permanent mitigation'. The relative permanence of these protections should be in line with the species' life history and impact avoidance dynamics.

\section{Acknowledgments}

This work was funded by the UNC Institute for the Environment. This work does not necessarily represent the views of the Institute. All interpretations and conclusions are those of the authors.

\section{Author Contributions}

The authors contributed equally to this work. BenDor conceived of the article, reviewed plan documents and literature, and authored early drafts. Woodruff added critical intellectual content, reviewed plan documents and literature, and aided all stages of writing.

\section{Conflicts of Interest}

The authors declare no conflict of interest.

\section{References}

1. Madsen, B.; Carroll, N.; Kandy, D.; Bennett, G. 2011 Update: State of Biodiversity Markets; Forest Trends: Washington, DC, USA, 2011.

2. McKenney, B.A.; Kiesecker, J.M. Policy development for biodiversity offsets: A review of offset frameworks. Environ. Manag. 2010, 45, 165-176.

3. Burgin, S. BioBanking: An environmental scientist's view of the role of biodiversity banking offsets in conservation. Biodivers. Conserv. 2008, 17, 807-816.

4. Bull, J.W.; Suttle, K.B.; Singh, N.J.; Milner-Gulland, E. Conservation when nothing stands still: Moving targets and biodiversity offsets. Front. Ecol. Environ. 2013, 11, 203-210. 
5. Poiani K.; Goldman, R.L.; Hobson J.; Hoekstra, J.M.; Nelson, K.S. Redesigning biodiversity conservation projects for climate change: Examples from the field. Biodivers. Conserv. 2011, 20, 185-201.

6. Hagen, C.A.; Pitman, J.C.; Loughin, T.M.; Sandercock, B.K.; Robel, R.J.; Applegate, R.D. Impacts of anthropogenic features on habitat use by Lesser Prairie-Chickens. In Ecology, Conservation and Management of Grouse; Sandercock, B.K., Martin, K., Segelbacher, G., Eds.; University of California Press: Berkeley, CA, USA, 2011; pp. 63-75.

7. Kyle, S.; Pitman, J.; Klute, D.; Beauprez, G.; Schoeling, D.; Janus, A.; Haufler, J. The Lesser Prairie-Chicken Range-wide Conservation Plan; Van Pelt, W.E., Ed.; Western Association of Fish and Wildlife Agencies: Cheyenne, WY, USA, 2013.

8. United States Fish and Wildlife Service (USFWS). Guidance for the Establishment, Use, and Operation of Conservation Banks; USFWS: Washington, DC, USA, 2003.

9. Gronewold, N. Texas, drillers gear up for long-term battle over endangered species. Available online: http://www.eenews.net/energywire/stories/1059994807/ (accessed on 9 January 2014)

10. National Resource Council. Compensating for Wetland Losses under the Clean Water Act; National Academy Press: Washington, DC, USA, 2001.

11. Robertson, M.; Mikota, M. Water quality trading and wetland mitigation banking: Different problems, different paths. Natl. Wetlands Newsl. 2007, 29, 9-15.

12. Raffini, E.; Robertson, M. Water quality trading: What can we learn from 10 years of wetland mitigation banking? Natl. Wetlands Newsl. 2005, 27, 3-5.

13. Drechsler, M.; Hartig, F. Conserving biodiversity with tradable permits under changing conservation costs and habitat restoration time lags. Ecol. Econ. 2011, 70, 533-541.

14. Salzman, J.; Ruhl, J.B. Currencies and the commodification of environmental law. Stanford Law Rev. 2000, 53, 607-694.

15. Kindlmann, P.; Burel, F. Connectivity measures: A review. Landsc. Ecol. 2008, 23, 879-890.

16. Van Teeffelen, A.J.A.; Vos, C.C.; Opdam, P. Species in a dynamic world: Consequences of habitat network dynamics on conservation planning. Biol. Conserv. 2012, 153, 239-253.

17. United States Fish and Wildlife Service (USFWS). Conservation Needs of the Lesser Prairie-Chicken; USFWS: Washington, DC, USA, 2012. Available online: https:/www.tpwd.state.tx.us/huntwild/ lesserprairiechicken /media/ fws_lpc_paper.pdf (accessed on 9 January 2014).

18. Drechsler, M.; Johst, K.; Ohl, C.; WäTzold, F. Designing cost-effective payments for conservation measures to generate spatiotemporal habitat heterogeneity: Payments for habitat heterogeneity. Conserv. Biol. 2007, 21, 1475-1486.

19. Hartig, F.; Drechsler, M. Smart spatial incentives for market-based conservation. Biol. Conserv. 2009, 142, 779-788.

20. Bedward, M.; Ellis, M.V.; Simpson, C.C. Simple modelling to assess if offsets schemes can prevent biodiversity loss, using examples from Australian woodlands. Biol. Conserv. 2009, 142, 2732-2742.

21. Quétier, F.; Lavorel, S. Assessing ecological equivalence in biodiversity offset schemes: Key issues and solutions. Biol. Conserv. 2011, 144, 2991-2999. 
22. Landry, M.; Siems, A.; Stedge, G.; Shabman, L. Applying Lessons Learned from Wetlands Mitigation Banking to Water Quality Trading; Office of Policy, Economics, and Innovation and Office of Water U.S. EPA: Washington, DC, USA, 2005.

23. Pickett, E.J.; Stockwell, M.P.; Bower, D.S.; Garnham, J.I.; Pollard, C.J.; Clulow, J.; Mahony, M.J. Achieving no net loss in habitat offset of a threatened frog required high offset ratio and intensive monitoring. Biol. Conserv. 2013, 157, 156-162.

24. Moilanen, A.; van Teeffelen, A.J.A.; Ben-Haim, Y.; Ferrier, S. How much compensation is enough? A framework for incorporating uncertainty and time discounting when calculating offset ratios for impacted habitat. Restor. Ecol. 2009, 17, 470-478.

25. BenDor, T. A dynamic analysis of the wetland mitigation process and its effects on no net loss policy. Landsc. Urban Plann. 2009, 89, 17-27.

26. Species Banking. Available online: http://us.speciesbanking.com/ (accessed on 9 January 2014).

27. Corps and EPA. Compensatory Mitigation for Losses of Aquatic Resources; Final Rule; Federal Register: Washington, DC, USA, 2008; 19593-19705.

28. California Air Resources Board. Compliance Offset Program. Available online: http://www.arb.ca.gov/ cc/capandtrade/offsets/offsets.htm (accessed on 9 January 2014).

(C) 2014 by the authors; licensee MDPI, Basel, Switzerland. This article is an open access article distributed under the terms and conditions of the Creative Commons Attribution license (http://creativecommons.org/licenses/by/3.0/). 